\title{
Attitude Towards Home-Based Management of Diarrhea and Associated Factors Among Mothers of Under-Five Children of Fagita Lekoma District, Northwest Ethiopia, 2020
}

\author{
Bogale Kassahun Desta \\ University of Gondar \\ Addise Bilal Muhye \\ University of Gondar \\ Kibret Asmare Melkie \\ University of Gondar
}

Esayas Alemshet Tekletsadik

University of Gondar

Bethlehem Assefa Kelkil

University of Gondar

Zerko Wako Beko ( $\square$ zerkowako1992@gmail.com )

University of Gondar

\section{Research Article}

Keywords: Mothers, Under-five children, attitudes, factors, home-based diarrheal management

Posted Date: February 11th, 2022

DOI: https://doi.org/10.21203/rs.3.rs-1272526/v1

License: (c) This work is licensed under a Creative Commons Attribution 4.0 International License.

Read Full License 


\section{Abstract}

Background: Diarrhea is the second most common cause of morbidity and mortality among children under 5 years old, following acute respiratory tract infection. Despite that home interventions can prevent $57 \%$ of mortality related to diarrhea. However, still mothers' attitudes towards home-based diarrheal management range from $39-78 \%$ as a result of different factors.

Objective: This study aimed at assessing attitudes towards home-based management of diarrhea and associated factors among mothers of under-five children attending health care institutions.

Methods: An institutional-based cross-sectional study was conducted. Systematic random sampling was used to select study participants. Data were entered using Epidata version 3.1 and exported to SPSS version 25. The result was presented in frequency and percentage using tables and figures. Binary logistic regression was used to analyze the data. Those variables with $p$-value $<0.2$ in bivariate were entered in multivariate analysis to avoid confounding variables whereby $p$-value $<0.05$ were considered as significantly associated.

Result: A total of 422 mothers were surveyed with a $100 \%$ response rate. The mean age of the mothers was $33 \pm 10$. Positive mothers' attitude was $51.9 \%$ with $95 \% \mathrm{Cl}(46.8,57.1)$. Maternal age ranges from 2535 years (AOR:3.27, 95\% Cl: 1.72,6.22), 36-45 years (AOR: $8.79,95 \% \mathrm{Cl}: 3.50,22.11$ ), age $>45$ years (AOR: $8.00,95 \% \mathrm{Cl}: 2.62,24.43$ ), being single (AOR $0.18,95 \% \mathrm{Cl}: 0.06,0.56)$, being divorced (AOR:0.25, 95\%Cl:0.08,0.81), primary education (AOR: $7.26,95 \% \mathrm{Cl}: 3.62,14,57$ ), Secondary and above (AOR:8.43, 95\%Cl:3.77,18.82), Daily labor (AOR:5.44, 95\%Cl:1.19, 24.96), Income level with 1001-3000 ETB and greater or equal to 3001ETB with (AOR:3.14, 95\%Cl:1.35, 7.29) and (AOR:4.06, 95\% Cl: 1.71, 9.66) respectively. Knowing about how to prepare ORS (AOR: 6.72, 95\%Cl: 3.62,12.48) were significantly associated variables with the out came variable in the multivariate regression

Conclusion: One in every two mothers had a favorable attitude in this study. Maternal age, marital status, maternal educational status, occupation, and knowing about the preparation of ORS were factors associated with mothers' attitude. The focus should be made on younger mothers, illiterate, unmarried couples, not knowing how to prepare ORS to boost mothers' attitude.

\section{Introduction}

Diarrhoea is a condition associated with the passage of three or more watery or loose stools in a single day(1). Annually according to the WHO reports more than 700 million episodes of diarrhoea in under-five children in developing countries(2). In the globe, diarrhoea is the second most common cause of morbidity and mortality among children under 5 years old, following acute respiratory tract infection $(3,4)$. Besides it is the leading cause of malnutrition in children under-5 years whereby around $60-70 \%$ of deaths are due to loss of water and essential minerals (5-7). 
It is an established fact that the Sustainable Development Goals (SDG-3) is targeted to reduce under-five mortality to 25 deaths per 1,000 live births by 2030 (8). However, Only 59 deaths per 1000 live births of under-5 mortality were achieved in the Ethiopian Mini Demographic Health Statistics (EMDHS) of 2019 (9). Consequently, Ethiopia was among the top 10 countries with an under-five mortality rate of 178 per 1000 live birth(8).

In Sub-Saharan Africa, the cases remain high due to poor perception of primary caregivers' management of diarrhea especially mothers $(10,11)$. Studies showed that positive mothers' attitudes towards homebased management of diarrhea (HBMD) range from 39-78\% (12-18). Home-based fluids include, a mixture of salt, sugar, and water, breast milk, Gruels (diluted mixtures of cooked cereals and water), soup, rice water. Proper home-based interventions of diarrhea can prevent nearly three-fifth of mortality related to diarrhea. Hence, the more positive a mother's attitude causes fewer babies who will experience diarrhea. Consequently, it maintains good quality of life by reducing morbidity and mortality $(5,19-21)$.

There is very limited study on mothers' attitude towards home-based diarrheal management besides some uses attitude of mother's as a factor that could affect the practice home-based management of diarrhea. Studies suggested that the lack of mothers' attitudes was mainly influenced by social and cultural beliefs (22-25). Furthermore, factors like age of the mother, residence, knowledge of HBMD, being single, being less educated, being a housewife were found significantly associated with mothers' attitude towards home-based diarrheal management $(5,12,13,20,26,27)$.

Some of the techniques used to enhance mothers' attitude towards home-based diarrheal management were the provision of education for mothers regarding early home-based case management of childhood diarrhoea along with mobilization of community on home management of diarrhoea to increase awareness and improve practice level $(20,28)$. Thus, boosting the knowledge of mothers will improve their attitude toward diarrhoea management (5). The purpose of this study was to assess the attitude of mothers towards Home-based diarrheal management and associated factors in under-five children attending health centres of Fagita Lekoma District, Northwest Ethiopia, 2020

\section{Materials And Methods}

\section{Study Design, Period and setting}

An institutional based cross-sectional study was conducted from February to March 2020. The study area was Fagita Lekoma district, which is found in Awi Zone of Amhara Regional State and is located $472 \mathrm{~km}$ far from Addis Ababa, the capital city of Ethiopia, and $100 \mathrm{~km}$ far from Bahir Dar, the capital city of Amhara National Regional State. According to the district health office report in 2020, it has a total population of 169,205 of which the estimated number of under-five children was 22,839 . In this district, there are 6 health centers, 3 private clinics, and 27 health posts with 52 health extension workers which give health care services to the population in the district.

\section{Population}


All mothers attending under-five clinics whose child has an episode of diarrhea in the past three months were source population. Those mothers attending under-five clinics during the data collection period were a study population. Those mothers who were not volunteers to participate in the study and whose children need urgent referral were excluded.

\section{Sample Size Determination.}

The sample size for this study was calculated using a single population proportion formula based on the following assumptions:

$n=\left(Z_{\alpha / 2}\right)^{2} \times P(1-P) /(d) 2$, where $n$ is minimum sample size required for the study, $d$ is margin of error $=0.05, Z_{\alpha / 2}$ is value of standard normal distribution $(Z=1.96)$ with confidence interval of $95 \%$, and $\alpha$ is $0.05 ; P=$ favorable attitude $=50.1 \%(26)$

$n=(Z \alpha / 2) 2 \times(1-P) /(d)^{2}=(1.96)^{2} \times 0.501(1-0.501) /(0.05)^{2}=384$.

Therefore, by taking the nonresponse rate of $10 \%$, the total sample size required for this study was $384+$ $38=422$

\section{Sampling Procedure}

A systematic random sampling technique was employed to select the study participants from all health centers of Fagita Lekoma district. Based on the last three-month under-five health care services the average daily flow was calculated. The number of the under-five visits in the second quarter of the year of 2020 in Addis Kidamie, Finzit, Fagita, Waze, Gezehera, and Chiguali health centers was 1242, 341, 296, 801,264 , and 524 , respectively. Then, the number of actual study participants from each HC was calculated and taken proportionally by using the formula $n i=(n / N) \times N i$ (Figure 1).

\section{Operational definition}

Favorable attitude: Those who scored above mean on attitude questions(26)

Unfavorable attitude: Those who scored below mean on attitude questions(26)

Diarrhea: The passage of three or more watery or loose stools in a single day(1)

\section{Data Collection Method and Tool.}

Structured interview questionnaires were adapted and modified from differently related literature to collect the data on the Sociodemographic variables, attitude-related questions, and associated factors (27-30). It was prepared in English and then translated to Amharic language and then was retranslated into English to check for its consistency. The data were collected through a face-to-face interview by trained collectors. Four BSc nurses and one supervisor for data collection activities were recruited. 


\section{Data Quality Control.}

To assure the data quality, the recruited data collectors were trained for half days on the objective, confidentiality of information, the relevance of the study and respondent's right, pretest, informed consent, and techniques of an interview. Before going into data collection, the structured questionnaire was pretested on one private clinic for consistency of understanding the survey tool, and modifications were done accordingly. Close supervision was undertaken during data collection

\section{Data Processing and Analysis.}

Data were entered using Epi data version 4.6 software and analyzed using SPSS version 25. Data cleaning and cross-checking were done before analysis. Descriptive statistics were summarized using the mean, and standard deviation. Frequencies and percentages were used in the presented table, figures and text. Bivariate and multivariate analysis were used to identify factors associated with mothers attitudes towards home-based management of diarrhea in binary logistic regression.

\section{Results}

\section{Socio-demographic characteristics of mothers}

A total of 422 mothers were involved with a response rate of $100 \%$. More than two-fifth of $185(43.8 \%)$ respondents were aged between 25 and 35 years, almost all 420 (99.5\%) respondents were followers of orthodox religion. Majority of 342(92.4\%) respondents were Awi by ethnicity. More than three-quarters $327(77.5 \%)$ respondents were married. Nearly three-fifths $247(58.5 \%)$ respondents had $1-2$ numbers of children. Regarding educational status: about $248(58.8 \%)$ of respondents were illiterate. About

$277(65.6 \%)$ and $193(45.7 \%)$ respondents were housewives and earn monthly income greater than 3000 ETB respectively (Table 1).

Table 1: Socio-demographic characteristics of mothers in Fagita lekoma district, North West Ethiopia, 2020( $n=422)$ 


\begin{tabular}{|c|c|c|}
\hline Variables & Frequency & Percent \\
\hline \multicolumn{3}{|l|}{ Maternal Age } \\
\hline $15-24$ & 126 & 29.9 \\
\hline $25-35$ & 185 & 43.8 \\
\hline $36-45$ & 66 & 15.6 \\
\hline$>45$ & 45 & 10.7 \\
\hline \multicolumn{3}{|l|}{ Religion } \\
\hline Orthodox & 420 & 99.5 \\
\hline Other ${ }^{\mathrm{a}}$ & 2 & 0.5 \\
\hline \multicolumn{3}{|l|}{ Ethnicity } \\
\hline Amhara & 72 & 17.1 \\
\hline Awi & 342 & 81.0 \\
\hline Other ${ }^{b}$ & 8 & 1.9 \\
\hline \multicolumn{3}{|l|}{ Marital status } \\
\hline Married & 327 & 77.5 \\
\hline Single & 34 & 8.1 \\
\hline Widowed & 29 & 6.9 \\
\hline Divorced & 32 & 7.6 \\
\hline \multicolumn{3}{|l|}{ Number of children } \\
\hline $1-2$ & 247 & 58.5 \\
\hline $3-4$ & 153 & 36.3 \\
\hline$>4$ & 22 & 5.2 \\
\hline \multicolumn{3}{|l|}{ Educational status } \\
\hline Illiterate & 248 & 58.8 \\
\hline Primary school (1-8) & 64 & 24.4 \\
\hline Secondary and above & 150 & 16.8 \\
\hline \multicolumn{3}{|l|}{ Occupation } \\
\hline Housewife & 277 & 65.6 \\
\hline Government employee & 79 & 17.3 \\
\hline
\end{tabular}




\begin{tabular}{lcc} 
Private employee & 68 & 12.8 \\
Daily laborer & 18 & 4.3 \\
\hline Monthly income(ETB) & & \\
\hline$<=1000$ & 70 & 16.6 \\
$1001-3000$ & 193 & 45.7 \\
$>=3001$ & 159 & 37.7
\end{tabular}

Other $^{\mathrm{a}}=$ protestant, Muslim; Other $^{\mathrm{b}}=$ Oromo, tigre;

\section{Personal related variables}

More than three quarter 306(72.5\%) knew about HBDM, concerning sources of information about twothirds $213(66.4 \%)$ heard from healthcare professionals, more than half $306(72.5 \%)$ knew about how to prepare ORS at home (Table 2)

Table 2: Personal related variables of mothers in Fagita lekoma district, North West Ethiopia, 2020(n=422)

\begin{tabular}{lcc} 
Variables & Frequency & Percent \\
\hline Did you get information & on Home based diarrheal & management \\
\hline No & 116 & 27.5 \\
Yes & 306 & 72.5 \\
\hline Source of information & & \\
\hline Health professional & 213 & 66.4 \\
Media & 87 & 27.1 \\
Friends & 21 & 6.5 \\
\hline Knowing how to prepare ORS & & \\
\hline No, I don't know & 116 & 27.5 \\
Yes, I do & 306 & 72.5
\end{tabular}

\section{Attitude of mothers towards home-based management of diarrhea}

The mean attitude score of the study participants' was $21.03 \pm 4.00$. Majority $177(41.9 \%)$ of participants agreed that diarrhea is a problem in the community. Around 155(36.7\%) agreed that diarrhea is a curable disease. Ninety-seven 182 (43.1\%) participant's had agreed that diarrhea attacks mostly bottle-feed 
children, 205(48.6\%) agree cause diarrhea, 185(43.8\%) agreed that diarrhea can be managed at home, and nearly two-fifth $164(38.9 \%)$ agreed that vaccination can prevent diarrheal disease, $182(43.1 \%)$ had agreed on using mixed feeding before 6 months can cause diarrhea (Table 3 ).

Table 3: Attitude of mothers towards home-based management of diarrhea in under-five children in Fagita Lekoma district, North West Ethiopia, 2020( $n=422)$

$\begin{array}{lllll}\begin{array}{l}\text { Strongly } \\ \text { agree }\end{array} & \text { Agree } & \text { Neutral } & \text { Disagree } & \begin{array}{l}\text { Strongly } \\ \text { disagree }\end{array} \\ \text { Variables } & & & & \text {. }\end{array}$

\begin{tabular}{lccccc}
\hline $\begin{array}{l}\text { Diarrhea is a problem in the } \\
\text { community }\end{array}$ & $73(17.2 \%)$ & $104(24.6 \%)$ & $72(17.0 \%)$ & $128(30.3 \%)$ & $45(10.7 \%)$ \\
\hline $\begin{array}{l}\text { Diarrhea is a curable } \\
\text { disease }\end{array}$ & $85(20.1 \%)$ & $70(16.6 \%)$ & $108(25.9 \%)$ & $124(29.3 \%)$ & $35(8.3 \%)$ \\
\hline $\begin{array}{l}\text { Diarrhea attacks mostly } \\
\text { bottle-feed children }\end{array}$ & $29(6.9 \%)$ & $153(36.2 \%)$ & $88(20.8 \%)$ & $82(19.4 \%)$ & $70(16.6 \%)$ \\
\hline $\begin{array}{l}\text { Teething causes diarrhea } \\
\text { Diarrhea can be managed at }\end{array}$ & $111(26.3 \%)$ & $94(22.2 \%)$ & $70(16.6 \%)$ & $118(28.0 \%)$ & $29(6.9 \%)$ \\
\hline $\begin{array}{l}\text { home } \\
\text { Exclusive breast feeding can } \\
\text { prevent diarrhea }\end{array}$ & $123(29.1 \%)$ & $38(9.0 \%)$ & $111(26.3 \%)$ & $69(16.3 \%)$ & $81(19.2 \%)$ \\
\hline $\begin{array}{l}\text { Mixed feeding before 6 } \\
\text { months can cause diarrhea }\end{array}$ & $25(5.9 \%)$ & $157(37.2 \%)$ & $75(17.8 \%)$ & $79(18.7 \%)$ & $86(20.3 \%)$ \\
\hline $\begin{array}{l}\text { ORS and other fluid replace } \\
\text { fluid loss and electrolyte } \\
\text { imbalance }\end{array}$ & $67(15.9 \%)$ & $105(24.9 \%)$ & $68(16.1 \%)$ & $105(24.9 \%)$ & $67(15.9 \%)$ \\
\hline $\begin{array}{l}\text { Vaccination can prevent } \\
\text { diarrheal disease }\end{array}$ & $120(28.4 \%)$ & $44(10.4 \%)$ & $108(25.9 \%)$ & $71(16.8 \%)$ & $70(16.6 \%)$ \\
\hline $\begin{array}{l}\text { Hand washing, boiling water } \\
\text { and continuing feeding } \\
\text { prevent diarrhea }\end{array}$ & $33(7.8 \%)$ & $150(35.5 \%)$ & $81(19.2 \%)$ & $94(22.2 \%)$ & $64(15.1 \%)$ \\
\hline
\end{tabular}

\section{Prevalence mothers' attitude toward home-based management of diarrhea}

The prevalence of mothers attitude was $51.9 \%, 95 \% \mathrm{Cl}(46.8,57.1)$ and $48.1 \%, 95 \% \mathrm{Cl}(42.9,53.2)$ was favorable and unfavorable respectively (Figure 2).

Factors associated with mothers' attitude towards home-based management of diarrhea 
In bivariate analysis; maternal age, number of children, monthly income, marital status, maternal educational status, occupation, information on HBMD, and knowing about the preparation of ORS were factors associated with mothers' attitude on home-based management of diarrhea.

In Multivariate analysis; maternal age, marital status, maternal educational status, occupation, and knowing about the preparation of ORS were factors associated with mothers' attitude on home-based management of diarrhea. However number of children and monthly income were not statistically significant.

Maternal age ranges from 25-35 years (AOR:3.27, 95\% Cl: 1.72,6.22), 36-45 years (AOR: $8.79,95 \% \mathrm{Cl}$ : $3.50,22.11$ ), age $>45$ years (AOR: $8.00,95 \% \mathrm{Cl}: 2.62,24.43$ ), being single (AOR $0.18,95 \% \mathrm{Cl}: 0.06,0.56$ ), being divorced (AOR:0.25, 95\% Cl:0.08,0.81), primary education (AOR: $7.26,95 \% \mathrm{Cl}: 3.62,14,57$ ), Secondary and above (AOR:8.43, 95\%Cl:3.77,18.82), Daily labor (AOR:5.44, 95\%Cl:1.19, 24.96), Income level with 1001-3000 ETB and greater or equal to 3001ETB with (AOR:3.14, 95\%Cl:1.35, 7.29) and (AOR:4.06, 95\% Cl: $1.71,9.66)$ respectively. Knowing about how to prepare ORS (AOR: $6.72,95 \% \mathrm{Cl}: 3.62,12.48)$ were significantly associated variables with the out came variable in the multivariate regression (Table 4).

Table 4: Binary logistic regression analysis for factors affecting mothers' attitude towards home-based management of diarrhea in under-five children of Fagita Lekoma district, Northwest Ethiopia, 2020 
Variable

Maternal age

$15-24$

25-35

36-45

$>45$

\section{Unfavorable Favorable $\mathrm{AOR}(95 \% \mathrm{Cl})$}

\begin{tabular}{llll}
\hline $90(21.3 \%)$ & $36(8.5 \%)$ & 1 & 1 \\
\hline $77(18.2 \%)$ & $108(25.6 \%)$ & $3.27(1.72,6.22)$ & $0.000^{*}$ \\
\hline $20(4.7 \%)$ & $46(10.9 \%)$ & $8.79(3.50,22.11)$ & $0.000^{*}$ \\
\hline $16(3.8 \%)$ & $29(6.9 \%)$ & $8.00(2.62,24.43)$ & $0.000^{*}$
\end{tabular}

Marital status

Married

Single

$135(32.0 \%)$

$192(45.5 \%)$

1

Widowed

$28(6.6 \%)$

$6(1.4 \%)$

$0.18(0.06,0.56)$

$0.003^{*}$

Divorced

$\begin{array}{llll}18(4.3 \%) & 11(2.6 \%) & 0.48(0.16,1.40) & 0.181 \\ 22(5.2 \%) & 10(2.4 \%) & 0.25(0.08,0.81) & 0.021^{*}\end{array}$

Maternal educational status

Illiterate

Primary (1-8)

Secondary and above

Occupational status

Housewife

Government employee

Private employee

Other*

Monthly income

$<=1000$ ETB

1001-3000 ETB

$>=3001$ ETB

Number of children

1-2

3-4

\begin{tabular}{llll}
$148(35.1 \%)$ & $78(18.5 \%)$ & 1 & 1 \\
\hline $37(8 . .8 \%)$ & $56(13.3 \%)$ & $7.26(3.62,14.57)$ & $0.000^{*}$ \\
$18(4.3 \%)$ & $85(20.1 \%)$ & $8.43(3.77,18.82)$ & $0.000^{*}$
\end{tabular}

$133(31.5 \%)$

$144(29.8 \%)$

1

1

$27(6.4 \%) \quad 46(12.0 \%) \quad 1.15(0.53,2.50) \quad 0.730$

$33(7.8 \%)$

$21(8.0 \%)$

$2.24(0.88,5.71)$

0.093

$10(2.4 \%)$

$8(1.9 \%)$

$5.44(1.19,24.96) \quad 0.029 *$

\begin{tabular}{llll}
\hline $47(11.1 \%)$ & $23(5.5 \%)$ & 1 & 1 \\
\hline $99(23.5 \%)$ & $94(22.3 \%)$ & $3.14(1.35,7.29)$ & 0.008 \\
\hline $57(13.5 \%)$ & $102(24.2 \%)$ & $4.06(1.71,9.66)$ & 0.002 \\
\hline
\end{tabular}

\begin{tabular}{lllll}
-2 & $127(30.0 \%)$ & $120(28.4 \%)$ & 1 & \\
\cline { 2 - 5 } $3-4$ & $68(16.1 \%)$ & $85(20.1 \%)$ & $1.01(0.52,1.99)$ & 0.969
\end{tabular}


Knowing how to prepare ORS

\begin{tabular}{|lllll}
\hline No, I don't know & $94(22.3 \%)$ & $22(5.2 \%)$ & 1 & 1 \\
\hline Yes, I do & $109(25.8 \%)$ & $197(46.7 \%)$ & $6.72(3.62,12.48)$ & $0.000^{\star}$
\end{tabular}

*indicate significantly associated

\section{Discussion}

Understanding mothers' attitude is the principal element in understanding their intention to know and practice home-based management of diarrhea (31). Early management and recognition of danger signs are key strategies in treating diarrhoeal diseases at home(32). Based on the findings more than half of the participants had favorable attitude $51.9 \%, 95 \% \mathrm{Cl}(46.8,57.1)$. The current study is in line with a study conducted in Finote selam 50.1\%(26). The possible explanation might be due to similar socio-economic status. The current study is lower than studies in Pakistan(12, 32), Indonesia(13), and Yemen(14) with prevalence positive maternal attitude of $73.6 \%$ Indonesia $77.1 \%$, and Yemen $69.2 \%$ respectively. The possible explanation might be due to differences in a study setting, sample size, sampling techniques, socio-economic and cultural differences. However, in Indonesia assessed only an infant and that of Peshawar was conducted in private and public hospitals. That of Pakistan was conducted on urban dwellers among early child age. In Ethiopia, a study in Assosa 62.9\%(33), the possible explanation was a different study design which was community-based and sample size differences. The current study is higher than studies in Nepal Indian(16), Pakistan(32) and Ethiopia Dire Dawa(34) with 39\%,44.6\% and $45.1 \%$ respectively. The difference is due to study duration, sampling techniques, and sample size variation. However, a study in Nepal Indian study assessed only mothers' attitudes toward diarrhoea not on management. That of Pakistan was conducted rural residence in mothers among diarrhoea among early child age.

Mothers whose age group from 36-45 and >45 years were 7.79 and 9.55 times more likely to have a favorable attitude on home-based diarrheal management respectively, as compared to those mothers age groups from 15-24 years. This is supported by the studies conducted in Nigeria(29) and Ethiopia(26).The possible explanation might be due to as age of the mothers increase their experience toward diarrheal management increases.

In this study, being single and being divorced were about $82 \%$ and $75 \%$ are less likely to have a favorable attitude on home-based diarrheal management respectively, as compare to mothers who had married. This result is in line with a study conducted in Fenote Selam, Ethiopia(26). This may be due to most of husbands' were educated compared to mothers, an educated people have an increased levels of awareness and knowledge, due to gathering information from different sources this leads to good attitude and practice related to child health due to this reason when mothers are married, sharing of 
knowledge and support each other in different aspect of home-based activities including home-based diarrheal disease management.

This study also revealed that caregivers who have primary education and secondary and above education were 7.26 and 8.43 times more likely to have a favorable attitude respectively, as compared to illiterate. This study was supported by a previous study in Ethiopia(26). The fact is that highly educated mothers have higher access to information than mothers who are illiterate.

In this study, daily labour are about 5.44 times more likely to have favorable attitude on home-based diarrheal management as compared to housewife mothers. This could be due to the fact that they great connection with others through information sharing in their working areas.

In addition, those mothers who know about the preparation of ORS 6.72 times more likely to have favorable attitude about HBMD as compared to their counterparts. The possible justification might be those mothers knowing about the preparation of ORS also knowing the importance of ORS, how and when to give ORS to the child, this leads to increase maternal confidence on home-based management of diarrhea and develop favorable attitude on perception HBDM.

\section{Limitation}

Firstly, Due to cross-sectional nature of the study we could not determnine cause and effect at the same time. Secondly, There is a shortage of literature for factors associated with attitude of mothers

\section{Conclusion}

About half of the mothers had a favorable attitude in this study. Maternal age, marital status, maternal educational status, occupation, and knowing about the preparation of ORS were factors associated with mothers' attitude. The fo focus should be made on creating awareness and educating younger mothers, illiterate, unmarried couples, not knowing how to prepare ORS to boost mothers' attitude.

\section{Abbreviation And Acronyms}

AOR: Adjusted Odds Ratio, Cl: Confidence Interval, EMDHS: Ethiopian Mini Demographic Survey, ETB: Ethiopian Birr, HBMD: Home Based Management of Diarrheal, IRB: Institutional Review Board, ORS: Oral Rehydrated Salt, SDG: Sustainable Development Goal, WHO: World Health Organization

\section{Declarations}

\section{Ethics approval and consent to participate}

Ethical clearance was approved by the Institutional Review Board (IRB) of the School of Nursing University of Gondar. A permission letter was written to the district administrator's office. Then, the administrator allowed us to conduct the study. Informed consent is obtained from all the participants and 
from the parents of minors and illiterate participants. Confidentiality was maintained by avoiding registration of personal identifiers like name, resident identification, and also no raw data was given to any other person. All methods were carried out following relevant guidelines and regulations.

\section{Consent for publication}

Not applicable.

\section{Availability of data and materials}

The datasets used and/or analysed during the current study available from the corresponding author on request.

\section{Competing interests}

The authors declare that they have no competing interests.

\section{Funding}

Not applicable.

\section{Authors' contributions}

$\mathrm{BK}, \mathrm{ZW}, \mathrm{BM}$, and $\mathrm{AB}$ conceived and designed the study, analyzed the data, interpreted the data, and prepared the manuscript. KA and EA assisted in data analysis and sketch the figures and tables revised the manuscript. Finally, all authors read and approved the final manuscript.

\section{Acknowledgments}

Our gratitude goes to the School of Nursing, College of Medicine and Health Sciences, the University of Gondar for giving us the chance to conduct this research. Their deepest gratitude also goes to Fagita Lekoma district administrator for permitting us to conduct this research. They would also like to thank their data collectors and participants for their full commitment and timely collection.

\section{References}

1. Ghasemi AA, Talebian A, Masoudi Alavi N, Moosavi G. Knowledge of mothers in management of diarrhea in under-five children, in kashan, iran. Nurs midwifery stud. 2013;1(3):158-62.

2. Mohsin A, Raza AB, Ahmad TM. Knowledge, attitude and practices of the mothers regarding oral rehydration solution, feeding and use of drugs in childhood diarrhoea. Annals. 2009;15(1):38-42.

3. Black R, Fontaine O, Lamberti L, Bhan M, Huicho L, El Arifeen S, et al. Drivers of the reduction in childhood diarrhea mortality 1980-2015 and interventions to eliminate preventable diarrhea deaths by 2030. Journal of global health. 2019;9(2). 
4. Organization $\mathrm{WH}$. The treatment of diarrhoea: a manual for physicians and other senior health workers. World Health Organization, 20059241593180.

5. Sunanda G, Ramaiah D, Sadiq MMJ, Narayana G. Impact of structured educational program on maternal knowledge, attitude, and practice toward diarrhea management in children $<5$ years age in Anantapur District. CHRISMED Journal of Health and Research. 2017;4(3):186.

6. Gollar L, Avabratha K. Knowledge, attitude, and practice of mothers of under-five children regarding diarrheal illness: A study from coastal Karnataka. Muller Journal of Medical Sciences and Research. 2018;9(2):66-.

7. https://www.who.int/news-room/fact-sheets/detail/diarrhoeal-disease.

8. Organization(WHO) WH. Children: improving survival and well-being. 2020.

9. Institute EPH, ICF. Ethiopia mini demographic and health survey 2019: key indicators. Rockville, Maryland, USA: EPHI and ICF. 2019.

10. Alghadeer S, Syed W, Alhossan A, Alrabiah Z, Babelghaith SD, Al Arifi MN, et al. Assessment of Saudi Mother's Knowledge and Attitudes towards Childhood Diarrhea and Its Management. International Journal of Environmental Research and Public Health. 2021;18(8):3982.

11. Morse T, Chidziwisano K, Tilley E, Malolo R, Kumwenda S, Musaya J, et al. Developing a Contextually Appropriate Integrated Hygiene Intervention to Achieve Sustained Reductions in Diarrheal Diseases. Sustainability. 2019;11(17):4656.

12. Ashraf S, Bangash R, Wali H, Munir M, Fareed A, Abbas M, et al. Knowledge, attitude, and practice of mothers regarding home-based management of acute diarrhea in children under 5 years in selected private and public hospitals of Peshawar. Journal of Rehman Medical Institute. 2019;5(4):13-9.

13. Rosyida DAC, Hidayatunnikmah N. Maternal Attitude in the Handling of Diarrhea in Infant. Jurnal Medicoeticolegal Dan Manajemen Rumah Sakit. 2020;9(1):23-9.

14. Abdulla ON, Badulla WF, Alshakka M, Al-Abd N, Ibrahim MIM. Mothers Knowledge, Attitude and Practice Regarding Diarrhea and its Management in Aden-Yemen: A Cross-Sectional Study in Poor Resource Setting.

15. Subba NR. Traditional and Modern Maternal and Child Health Care Practices and Effects among Rajbanshi Community in Nepal 2017.

16. Mathias J. Sanjeev Kumar Shah. Age.20(23):21.9.

17. Mekonnen M, Bekele K, Jemal K, Hailu D, Tesfa B, Mulatu T. Prevalence of Oral Rehydration Therapy Use During the Diarrheal Episode and Associated Factors Among Mothers of Under-Five Children Visiting Public Health Facilities in North Showa Zone, Oromia Region, Ethiopia. Patient preference and adherence. 2021;15:423.

18. Workie HM, Sharifabdilahi AS, Addis EM. Mothers' knowledge, attitude and practice towards the prevention and home-based management of diarrheal disease among under-five children in Diredawa, Eastern Ethiopia, 2016: a cross-sectional study. BMC pediatrics. 2018;18(1):1-9. 
19. Desta BK, Assimamaw NT, Ashenafi TD. Knowledge, practice, and associated factors of home-based management of diarrhea among caregivers of children attending under-five clinic in Fagita Lekoma District, Awi Zone, Amhara Regional State, Northwest Ethiopia, 2016. Nursing research and practice. 2017;2017.

20. Kebede Fufa W, Berhe Gebremedhin G, Gebregergs GB, Marama Mokonnon T. Assessment of poor home management practice of diarrhea and associated factors among caregivers of under-five years children in urban and rural residents of Doba Woreda, Ethiopia: Comparative cross-sectional study. International journal of pediatrics. 2019;2019.

21. Nasution Z, Samosir RF. Pengetahuan dan sikap ibu tentang penanganan diare di puskesmas polonia medan. Jurnal Darma Agung Husada. 2019;5(1):46-51.

22. Ebissa B. HOME BASED MANAGEMENT OF DIARRHEA AMONG MOTHERS OF UNDER FIVE CHILDREN IN JIMMA, ETHIOPIA. International Journal of Medical Studies. 2019;4(4).

23. Naseem A, Swetha R. Knowledge attitude and practice of childhood diarrhea and ORS administration in diarrhea amongst mothers of children below age 5 years. J Pediatr. 2016;3(6):416-20.

24. Abadi MFKA, Hujail SAAR, Shaimaa Mahdi H. Original paper Assessment of Mothers' Knowledge, Attitude, and Practice about Oral Rehydration Solution in Treatment of Diarrhea in Karbala.

25. Mallick AK, Bangari J, Kumar SS, Suyal H. Knowledge, attitude and practice of acute diarrheal disease and use of oral rehydration therapy among mothers of under five children. 2019.

26. Amare D, Mullu G. Mothers' Attitude Towards Childhood Diarrhea Management and Prevention in Under Five Children in Fenote Selam Town, West Gojjam, Amhara, Northwest Ethiopia. Science Journal of Public Health. 2015;3(3):398-403.

27. Mumtaz Y, Zafar M, Mumtaz Z. Knowledge attitude and practices of mothers about diarrhea in children under 5 years. Journal of the Dow University of Health Sciences (JDUHS). 2014;8(1):3-6.

28. Shah MS, Ahmad A, Khalique N, Afzal S, Ansari MA, Khan Z. Home-based management of acute diarrhoeal disease in an urban slum of Aligarh, India. The Journal of Infection in Developing Countries. 2012;6(02):137-42.

29. Ogunrinde OG, Raji T, Owolabi OA, Anigo KM. Knowledge, attitude and practice of home management of childhood diarrhoea among caregivers of under-5 children with diarrhoeal disease in Northwestern Nigeria. Journal of tropical pediatrics. 2012;58(2):143-6.

30. Masiha SA, Khalid A, Malik B, Shah SMA. Oral rehydration therapy-knowledge, attitude and practice (KAP) survey of Pakistani mothers. Journal of Rawalpindi Medical College Students Supplement. 2015;19(1):51-4.

31. Gathogo LW. Determinants of Home Management of Diarrhea among Care Givers of Children Below 5 Years in Ngandu Location, Nyeri County: JKUAT-COHES; 2021.

32. Gul R, Amin R. Knowledge, Attitude and Practice of Mothers Regarding Management of Diarrhea in Children of Early Age. Journal of the Dow University of Health Sciences (JDUHS). 2011;5(3):129-31.

33. Nigatu Merga1 TA. Knowledge, Perception, and Management Skills of Mothers with Under-five Children about Diarrhoeal Disease in Indigenous and Resettlement Communities in Assosa District, 
Western Ethiopia. Journal of health, population, and nutrition. 2015; Volume 33 (Number 1).

34. Workie HM, Sharifabdilahi AS, Addis EM. Mothers' knowledge, attitude and practice towards the prevention and home-based management of diarrheal disease among under-five children in Diredawa, Eastern Ethiopia, 2016: a cross-sectional study. BMC pediatrics. 2018;18(1):358-

\section{Figures}

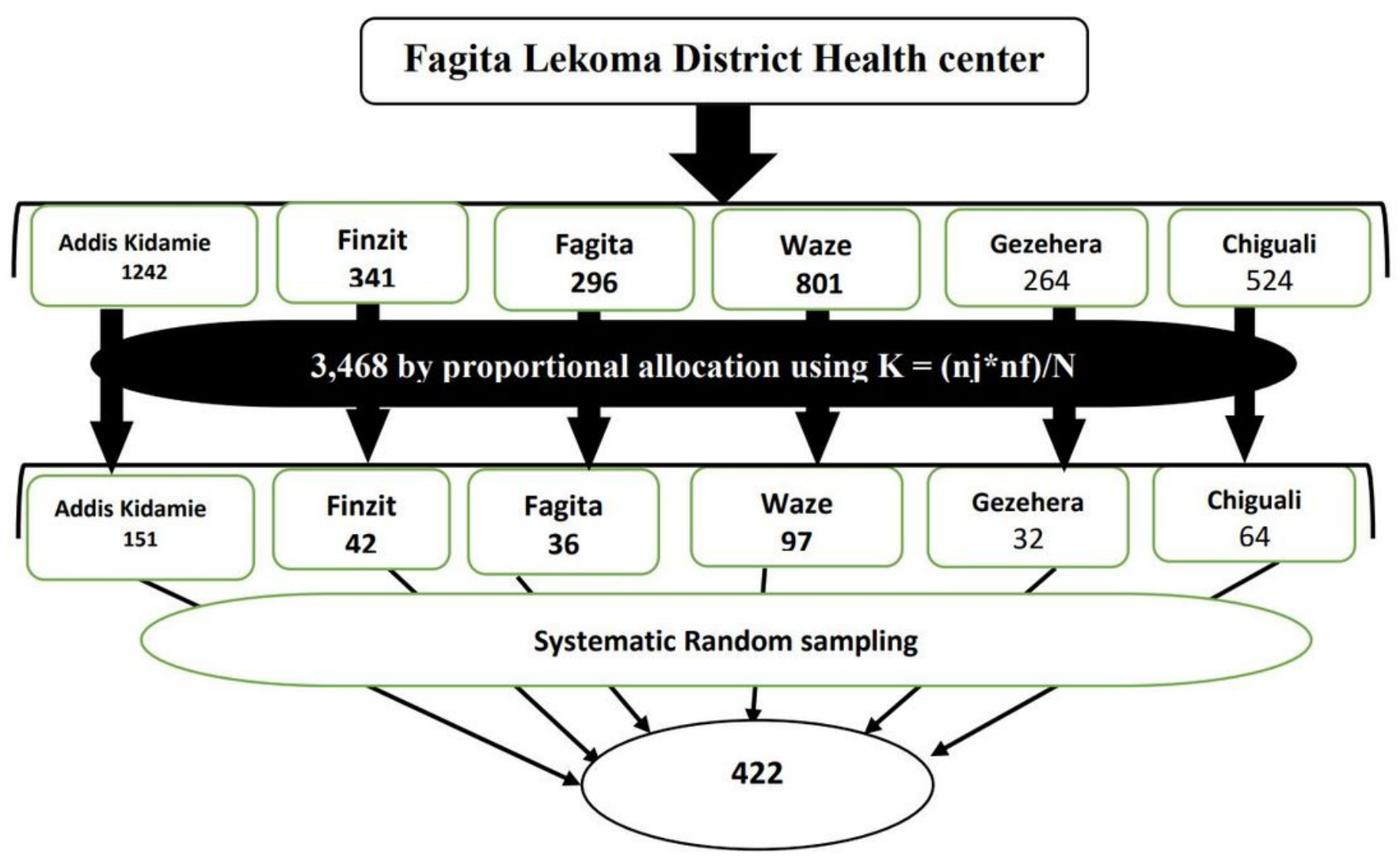

Figure 1

Schematic presentation of the sampling procedure. 


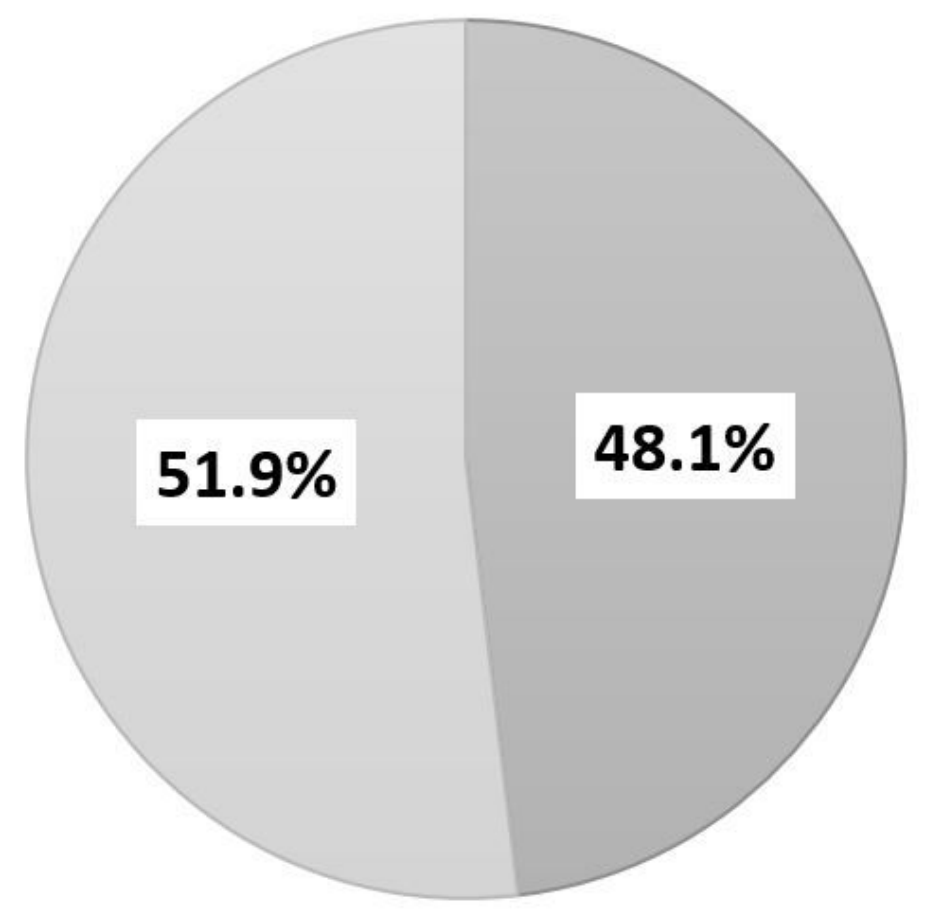

\section{$\square$ Unfavourable Attitude $\square$ Favourable Attitude}

Figure 2

proportion of attitude of mothers towards home-based management of diarrhea in under-five children in Fagita lekoma district, North West Ethiopia, 2020( $n=422)$ 